\title{
EL ANÁLISIS DE LAS FICCIONES PUBLICITARIAS COMO HERRAMIENTA DE LA ALFABETIZACIÓN AUDIOVISUAL .
}

\author{
Laia Falcón ${ }^{2}$ \\ Universidad Complutense de Madrid \\ Ifalcon@ccinf.ucm.es
}

Material original autorizado para su primera publicación en la revista académica REDMARKA. Revista Digital de Marketing Aplicado.

https://doi.org/10.17979/redma.2013.01.011.4748

Recibido: 16 Septiembre 2012

Aceptado 13 Diciembre 2012

\section{RESUMEN}

Los discursos publicitarios tienen en común importantes códigos y recursos con la ficción y la escritura mediática, y por tanto comparten también con éstas ciertos posibles riesgos para los receptores más jóvenes (sobre la violencia, los estereotipos o los consumos abusivos, por ejemplo) pero, a su vez, pueden convertirse en herramientas y materiales de análisis de extraordinario valor y eficacia para la alfabetización audiovisual. En este artículo se resumen ambas dimensiones y se propone la alfabetización audiovisual concentrada en esta especial relación entre publicidad y ficción como herramienta educativa, para reducir sus posibles riesgos e incrementar las oportunidades que brinda para las habilidades discursivas y reflexivas de niños y adolescentes. Como concreción de este principio se expone la utilización de la alfabetización audiovisual en torno a la publicidad llevada a cabo en el programa de prevención de conductas de riesgo "Prevenir en Madrid", elaborado entre 2001

\footnotetext{
${ }^{1}$ El programa "Prevenir en Madrid" al que se hace referencia en este artículo de investigación se ha desarrollado en el marco de un convenio entre la Universidad Complutense y el Instituto de Adicciones de Madrid Salud del Ayuntamiento de Madrid.

${ }^{2}$ Profesora e investigadora del Departamento de Comunicación Audiovisual y Publicidad I en la Facultad de Ciencias de la Información de Universidad Complutense de Madrid. Doctora en Comunicación Audiovisual por la Universidad Complutense de Madrid y en Sociología del Arte por la Universidad Sorbonne de París. Docente en las asignaturas de "Realización Audiovisual", "Dirección Cinematográfica", "Creatividad Publicitaria", "Dirección de Arte en Publicidad" y "Estructura del Sistema Audiovisual".
} 
y 2004 y desarrollado desde entonces hasta 2012 en los centros que imparten Educación Secundaria en Madrid capital, donde las actividades de análisis crítico, evaluación y elaboración de textos publicitarios con adolescentes se ha comprobado como una herramienta educativa de enorme eficacia tanto en materia de prevención como en la propia adquisición de destrezas de recepción mediática y decodificación del lenguaje publicitario.

Palabras clave: publicidad, alfabetización audiovisual, educación.

\begin{abstract}
ADVERTISING FICTION ANALYSIS AS A TOOL FOR AUDIOVISUAL ALPHABETIZATION

Advertising language share a number of codes and writing tools with fiction and media. Therefore they also share both the risks for younger audiences linked to stereotypes or confusing messages and, on the other hand, the quality of becoming materials and examples of extraordinary value for educative activities on media literacy. This article focuses on the special relationship between advertising and fiction as an educational tool, to increase the opportunities for children and teenagers to develop skills of media literacy on prevention of risk behaviours. As an application of this principle, the article exposes the conclusions obtained by the programme "Preventing in Madrid", developed in the high schools of Madrid between 2001 and 2012, where the activities of critical analysis, evaluation and development of advertising messages and processes with teenagers have been proved as an effective educational tool both in prevention of risk behaviour and in media literacy.
\end{abstract}

Key words: Advertising, Media literacy, Education. 


\section{El poder socializador de las ficciones publicitarias}

\subsection{La ficción como herramientas de escritura publicitaria}

La publicidad mantiene con el campo de la ficción -terreno pactado para la imaginación, la simulación y la exposición de cuestiones inventadas (Rodríguez Merchán, 1994,1996)- estrechos lazos de interdependencia que se activan a muy distintos niveles. Podríamos incluir aquí el propio nexo entre publicidad y ficción que se establece en torno a los objetivos principales de reclamo y seducción de los mensajes publicitarios (Eguizábal, 2007) y que implican una constante orientación a presentar la mejor faz posible de los productos anunciados mediante diversas estrategias de maquillaje, acentuación o modificación de alguna de sus auténticas características: éste es ya un primer terreno de alteración y corrección -relativamente conocido y aceptado por el receptor de mensajes- que puede manejar distintos grados y licencias de separación entre las representaciones publicitarias y las propiedades reales de los artículos anunciados; siempre que esta distancia entre la representación y lo representado se establece desde una conciencia compartida por emisor y receptor ( $y$ no cruza, por tanto, la frontera ética del engaño), se reconoce y admite como convención fundamental del lenguaje publicitario y se aceptan para ella estrategias y mecanismos de enunciación comunes a los códigos de distintos géneros de la ficción visual y narrativa. Además, la publicidad de mayor difusión se asocia con diversos lenguajes de escritura (como los utilizados, por ejemplo, por los distintos soportes audiovisuales), cuyo propio proceder expresivo implica muy diversos gradientes y mecanismos de metáfora, simulación y fingimiento plenamente insertos también en el campo de la ficción: una gran parte de la escritura utilizada en la publicidad que se difunde por medios de comunicación de masas o nuevas tecnologías se asocia con los procesos de recreación, codificación y manipulación de imágenes y sonidos que dichos medios utilizan cotidianamente para la confección de sus mensajes, tan dispares como pueden ser el recurrir a actores (que simulan el papel de expertos, fabricantes o consumidores satisfechos), modificar el aspecto de los productos y sus supuestos usuarios (mediante procesos de 
iluminación, realización o posproducción) o, simplemente, ambientar sus presentaciones en marcos sugerentes y cautivadores (que quizás nada tienen que ver con los ámbitos y situaciones reales de utilización de tales productos). En la actitud del espectador a la hora de leer determinados mensajes publicitarios se produciría idealmente un pacto de decodificación parecido al que (en mayor o menor grado) establece cuando es receptor de mensajes de ficción: si sabe que las reglas de lo verosímil y lo creíble se adaptan y modifican de acuerdo a las convenciones de los diferentes géneros comunicativos, puede interpretar los mensajes en consecuencia. La ficción narrativa y la publicidad tienen en común este marco de convenciones de escritura y lectura según el cual el emisor utiliza determinadas licencias comunicativas que deben ser comprendidas por el receptor para que la comunicación se desarrolle de forma completa: la recepción eficaz de una película musical, por ejemplo, parte de una cierta capacidad previa de decodificación, según la cual los espectadores conocen y entienden las convenciones generales del lenguaje cinematográfico (como son el significado de una elipsis por montaje o de la música no diegética) y las que pertenecen al propio género expresivo en que se inserta la narración (con peculiaridades tales como que los personajes interrumpan una acción y comiencen a cantar y a bailar en entornos y situaciones donde, en "la normalidad de la vida real", nunca se procede de tal manera); en un proceso muy parecido, gran parte de los lenguajes publicitarios argumentan y construyen sus discursos y recursos asumiendo el presupuesto de que la gran mayoría de sus receptores conocen las convenciones y fórmulas retóricas de este tipo de mensajes (y que pueden así, por ejemplo, establecer el marco adecuado de lectura que permite decodificar el mensaje que define un refresco como "la chispa de la vida" o el que promete una célebre actriz o modelo al contarnos, como acto de confianza del que podemos beneficiarnos, que determinado producto es "el secreto" de su belleza).

Sin embargo, tanto en el campo de la ficción como en el de los diversos lenguajes audiovisuales y el de los distintos tipos de discursos publicitarios, muchos de los gradientes o matices de esta simulación, fantasía o invención no 
siempre resultan tan evidentes para todos los receptores o, al menos, no de forma eficaz cuando la recepción se establece en actitud relajada de ocio y descanso (marco habitual para este tipo de mensajes): frente a un spot televisivo, por ejemplo, o una película de acción donde atractivos protagonistas lucen impecables trajes de chaqueta mientras realizan extremas acciones de movimiento y peligro, puede que algunos espectadores (sobre todo los más jóvenes) no detecten nada inverosímil ni artificioso aunque sí queden fascinados por la elegancia y contundencia de la imagen representada; es fácil que otro tipo de receptor sí identifique lo ficticio de estas representaciones, y que las entienda como licencias expresivas propias del lenguaje publicitario o del citado género narrativo; entre éstos, además, algunos pueden saber o intuir que probablemente fueron necesarios muchos trajes distintos para que cualquiera de estos dos ejemplos simulase frente a las cámaras que el modelo o el actor sólo habría lucido un único atuendo, siempre limpio y bien planchado; pero ya será mucho menor el porcentaje de espectadores que detecte (o recuerde en ese particular momento de recepción relajada) que determinados elementos de la apariencia del modelo o el actor (la perfección de su piel, el brillo y color del cabello e incluso la imagen de muchas partes del cuerpo representado) pueden ser resultado de la utilización de efectos de montaje y posproducción, capaces de reunir virtudes de varias personas como si fueran de una sola y de borrar o cambiar apariencias hasta dar con el resultado más atractivo; por último, y en un margen aún más reducido, sólo algunos receptores establecerán una relación entre estas representaciones y otras parecidas que hayan podido observar, reflexionando acerca de aspectos como, por ejemplo, las características sociales, geográficas y económicas que este tipo de imágenes asocian con más frecuencia a tales figuras elegantes, dinámicas y poderosas, preguntándose tal vez acerca de las posibles razones y consecuencias que estas decisiones pueden tener para cuestiones como la visibilidad cultural o la igualdad entre etnias, géneros o clases sociales. Desde décadas, la alfabetización audiovisual aborda tareas con las que, en diversos contextos educativos y con especial atención a los mensajes publicitarios y a la ficción mediática, ayudar a que los distintos tipos de receptores desarrollen destrezas con las que conocer y detectar los mecanismos y recursos de 
expresión utilizados por los medios audiovisuales: mediante el análisis activo y crítico de sus enunciados y procedimientos, los receptores disponen de un nivel mucho más maduro, consciente y protegido frente al impacto y las posibles consecuencias que algunos de estos textos -con sus citadas licencias retóricas, de selección, simulación o ficción- pueden influir en nuestras expectativas y modo de entender el mundo que nos rodea (Clifford, Gunter y Mcaleer, 1995; Clarembeaux, 2008 y 2010; Corroy, 2008). Es éste un objetivo de enorme importancia para muy diversos tipos de espectadores y consumidores, pero que alcanza un grado de especial urgencia en el caso de aquéllos que -como los niños o los adolescentes- se encuentran en una etapa de especial vulnerabilidad frente a las formas y contenidos de tales mensajes, no sólo porque sus destrezas de decodificación aún no han podido desarrollarse suficientemente, sino porque además se encuentran en una fase esencial en la construcción de la identidad, buscando y adoptando modelos externos con una fuerza mucho mayor que en otras edades.

\subsection{La influencia de la publicidad y la ficción audiovisuales}

Los sucesivos cambios comunicativos originados por la Revolución Tecnológica debilitan la eficacia de las barreras físicas creadas en la revolución anterior -la Industrial-, exponiendo a los niños y adolescentes con demasiada frecuencia a determinados riesgos a través de las nuevas tecnologías. Esta situación -que ha llevado a temer por la "desaparición de la infancia" (Postman, 1994) como una etapa diferenciada y protegida de los problemas existentes en el mundo de los adultos- demanda una reacción inmediata con la que superar estos riesgos mediante la consolidación de nuevas barreras, además de las físicas, que sigan protegiendo a la infancia en el nuevo contexto (Buckingham, 2000, 2003): entre ellas, destacarían, en primer lugar, la potenciación de la reflexión y el análisis crítico de lo que llega a través de las nuevas tecnologías $y$, en segundo, la reducción de aquellos contenidos destructivos que con tanta frecuencia llegan a la infancia a través de las pantallas. ¿Hasta qué punto influyen las formas y contenidos de estos discursos mediáticos en los niños y adolescentes? Para considerar la respuesta a esta pregunta resultan 
especialmente significativas las conclusiones de los estudios llevados a cabo sobre la influencia de la televisión en la violencia, el problema más estudiado en este ámbito (Bandura, 1979; Huesmann, 2003; Paik y Comstock, 1994; Potter, 1999): en lo que respecta a la influencia a corto plazo, los estudios llevados a cabo sobre este tema desde hace décadas (Geen y Thomas, 1986), vienen comprobando repetidamente que los comportamientos y actitudes que los niños observan en la televisión, tanto de tipo positivo (la solidaridad, la tolerancia...) como de tipo negativo (la violencia...), influyen en los comportamientos que manifiestan inmediatamente después, detectándose una tendencia significativa a imitar lo que acaban de ver en la televisión), conclusión de la que se deriva la necesidad de protegerlos de los contenidos destructivos, pero también la posibilidad y conveniencia de utilizar la tecnología audiovisual como punto de partida de actividades educativas; en lo que concierne a la influencia a largo plazo, en estudios longitudinales recientes con datos policiales y sobre violencia doméstica (Huesmann et al, 2003) se ha observado que la cantidad de violencia televisiva vista durante la infancia permite predecir la cantidad de violencia ejercida en la edad adulta. Las conclusiones de estos estudios coinciden en que las causas de esta influencia tan fuerte en los comportamientos y conductas posteriores son múltiples y complejas, dependientes también del resto de las relaciones que el niño y el adolescente establecen con otras figuras de referencia y a partir de las cuales interpretan todo lo que les rodea (incluido lo que reciben de los medios) y del tiempo de recepción que mantienen con respecto a estos canales y mensajes. Para comprender el impacto que el consumo prolongado de televisión o internet puede tener en algunas de las actuales dificultades de la infancia y la adolescencia, conviene recordar que ambas prácticas son conductas cotidianas que exigen muy poco esfuerzo (apretar un botón y mirar hacia la pantalla), mientras que dejarlas para realizar otra actividad (leer, comunicarse con los demás, llevar a cabo una actividad artística o manual...) supone bastante más esfuerzo: captan la atención proporcionando entreteniendo de forma casi inmediata, al contrario de lo que sucede con el resto de las actividades que los niños necesitan llevar a cabo para desarrollarse adecuadamente (inventar un plan para jugar, ponerse de acuerdo con los demás para cooperar, 
concentrarse para estudiar...), que exigen bastante más tiempo y esfuerzo hasta que producen cierta satisfacción y son difíciles de iniciar pero fáciles de abandonar (Cembranos, 2004). No es de extrañar, por tanto, que el hecho de pasar mucho tiempo de exposición a estas pantallas esté relacionado con algunos de los problemas de la infancia y la adolescencia que más preocupan hoy, como es, por ejemplo, la excesiva orientación al presente, que impide movilizar el esfuerzo y energía necesarios para construir el futuro. En este sentido cabe interpretar los resultados obtenidos en las distintas ediciones del estudio "Juventud en España": en el año 2000 el 66\% de los jóvenes de 15 a 29 años se manifestó de acuerdo con que "el futuro es tan incierto que lo mejor es vivir al día", encontrando que este presentismo se producía sobre todo entre quienes pasaban mucho tiempo viendo la televisión, sentían que fracasaron en la escuela primaria o secundaria y leían poco (Martín Serrano y Velarde Hermida, 2001); en el informe de 2005 (Aguinaga et al., 2005) se observa que el porcentaje de jóvenes que estaba de acuerdo con dicha creencia (el 68,9\%) había aumentado ligeramente respecto al detectado cuatro años antes.

En relación a esta fuerte influencia de los contenidos y formas transmitidos a niños y adolescentes mediante la publicidad, la ficción audiovisual y la asociación de ambas, destacan una serie de discursos y tratamientos que resultan especialmente peligrosos para el adecuado desarrollo físico y mental de tales receptores. En primer lugar encontramos probablemente la propia orientación general al consumo y la posible tendencia que de éste se deriva a buscar gratificaciones inmediatas, por encima de otro tipo de valores más difíciles de conseguir, y que no se pueden comprar (Jessor, 1992; Catalano y Hawkins, 1996; Megias, 2000). Ocupan un lugar muy relevante también aquellos anuncios y narraciones cuyos protagonistas emplean distintos tipos de violencia (contra sí mismos, como la anorexia o el consumo de sustancias de riesgo, o contra otros, como la agresión o exclusión de otras personas) al mismo tiempo que poseen valores con los que los niños y adolescentes se identifican, como la simpatía, el poder, la valentía o la popularidad (Bandura, 1979; Donnerstein, 1998; Martínez Benlloch, 2002). En tercer lugar destacan las representaciones publicitarias o narrativas que se asocian con la creación o 
consolidación de estereotipos y problemas de identidad mediante los nuevos códigos de "telebasura", que captan la atención mediante la explotación mucho más allá de los límites existentes hasta entonces- "del morbo, el sensacionalismo y el escándalo" (Plataforma por una Televisión de Calidad, 2006) e incrementan el riesgo de reducción del valor de las personas a características superficiales o efímeras, como la apariencia física, en detrimento de otras cualidades más esenciales y permanentes, como la empatía, la capacidad para respetar a los demás, la inteligencia o la ética. En cuarto lugar, numerosos estudios subrayan el peligro de aquellos anuncios y relatos que abundan en contenidos sexistas mediante la reproducción de los rígidos estereotipos de lo masculino y lo femenino presentados como pilares inamovibles de la dualidad de la existencia humana (Bakan, 1966; Bengoechea, Díaz-Aguado, Falcón et al., 2005). Por último, otro grupo importante de investigaciones detecta el peligro que se desprende de aquellas comunicaciones narrativas y publicitarias donde el etnocentrismo se representa como valor absoluto, que incrementa el riesgo de xenofobia, racismo y otras formas de intolerancia (Martín Serrano, 1990).

\section{El análisis crítico de la relación entre publicidad y ficción como herramienta educativa}

Como reflejan la mayoría de las citadas investigaciones sobre los riesgos de los medios audiovisuales para los receptores más jóvenes, determinados códigos y licencias desplegados por ciertos mensajes publicitarios ejercen una poderosa influencia en la construcción de significados, modelos de referencia y creencias normativas, que pueden ser utilizados después en la regulación de los comportamientos. Estas conclusiones no sólo subrayan la necesidad de proteger a niños y adolescentes de determinadas formas y contenidos, además ponen de manifiesto la posibilidad y conveniencia de utilizar los textos publicitarios como punto de partida de actividades educativas, para favorecer la eficacia de la educación en valores y en la prevención de importantes problemas sociales como la violencia de género, el racismo y la xenofobia o el consumo de sustancias dañinas para el desarrollo. 
Como reflejo del papel de la publicidad audiovisual en esta dirección, cabe considerar los resultados del estudio sobre sexismo y violencia de género realizado con adolescentes (Díaz-Aguado y Martínez Arias, 2001), en el que se comprueba la fuerte relación existente entre la superación de creencias que justifican la violencia de género y los mensajes trasmitidos por campañas publicitarias de concienciación y por determinados programas de ficción audiovisual comprometidos con ellas: existe un acuerdo muy generalizado entre los adolescentes con que la violencia de género es uno de nuestros principales problemas sociales (superando la tradicional tendencia a reducirlo a una cuestión privada) y con que la víctima debe denunciar la violencia, dos de los mensajes en los que más han insistido las campañas emitidas por televisión. Otro importante resultado detectado por el estudio es que los esquemas y conceptos utilizados por los adolescentes respecto a la violencia de género reflejan una influencia significativa de la televisión, superior a la de la escuela: la mayoría manifiesta cierta comprensión, aunque sea incompleta e imprecisa, de conceptos muy habituales en la televisión sobre este tema (como son los relacionados con el acoso sexual, la especificidad de la violencia de género y las causas y posibles soluciones a este problema), pero parecen desconocer de dónde viene esta situación, cuál ha sido su evolución histórica o por qué hay menos mujeres en los puestos desde los que se organiza la sociedad, carencias derivadas de la todavía considerable invisibilidad de las mujeres en la Historia enseñada en la escuela. Para valorar estas observaciones conviene tener en cuenta que también entre la población adulta parece tener una influencia decisiva en este tema los mensajes difundidos a través de campañas publicitarias, relatos de ficción o programas informativos en los principales medios de comunicación: así cabe interpretar los resultados obtenidos en las encuestas europeas desde hace dos décadas (Eurobarómetro de la Comisión Europea, 1999), en las que se detecta que la principal fuente de información sobre la violencia doméstica y de género han sido los medios de comunicación (la televisión en el $89 \%$ de los casos, la prensa en el $65 \%$ y la radio en el $44 \%$ ) y que a ellos corresponde en buena parte la progresiva debilitación del tradicional tabú a tratar esta cuestión en la vida cotidiana. 
Las investigaciones sobre programas de prevención de la violencia con adolescentes realizadas durante la última década (Díaz-Aguado, 2001, 2004) nos han permitido comprobar la utilidad que el material publicitario audiovisual, adecuadamente seleccionado, puede tener como complemento de extraordinario valor junto a otros instrumentos (como la bibliografía especializada, las explicaciones del profesorado o la discusión entre compañeros). Entre las ventajas que, en este sentido, puedan tener la tecnología audiovisual y los distintos códigos manejados por la ficción publicitaria, cabe destacar su fuerte concentración expresiva y metafórica, la facilidad con que favorece un mayor impacto emocional ( $\mathrm{y}$, por lo tanto, una mayor pregnancia), su capacidad de estimulación de la empatía y el modo en que facilita que el conjunto de la clase, incluso en contextos especialmente heterogéneos, comparta sus mensajes (pudiendo llegar hasta aquellos alumnos con dificultades para atender a otros tipos de información, entre los que suelen encontrarse los que tienen mayor riesgo, ya que son precisamente los que manifiestan una menor dedicación a la lectura y a las explicaciones del profesorado). Estas cualidades convierten a los materiales publicitarios audiovisuales en un punto de partida de enorme las actividades educativas (como la reflexión compartida con toda la clase, el trabajo cooperativo o el debate en pequeños grupos) y subrayan además la importancia de la alfabetización audiovisual como herramienta para el desarrollo de una capacidad crítica y de reflexión, no sólo en lo concerniente a los discursos difundidos por los diversos canales de comunicación, sino extensible también a los propios temas tratados por las campañas. Desde este punto de vista la alfabetización en los códigos y recursos de los distintos tipos de ficción audiovisual (con especial atención a los publicitarios) pasa a ser reconocida como un objetivo en sí misma para adaptar la educación a las exigencias de la sociedad mediática del siglo XXI (Buckinghan, 2003): ya que el objetivo general de la educación es la trasmisión del bagaje acumulado por la humanidad (para que cada individuo pueda apropiarse de las destrezas que le permitan encontrar su lugar en el mundo, y contribuir a mejorarlo) y nadie duda de la relevancia que en este sentido tiene la alfabetización en herramientas básicas como la lectura y la escritura, también es evidente hoy la necesidad de añadir la alfabetización en 
las nuevas tecnologías y códigos, imprescindible para adaptarse a los vertiginosos cambios de la revolución tecnológica, incrementando las oportunidades que éstos pueden proporcionar y protegiendo contra los riesgos que encierran (Potter, 2001).

Para que la escuela pueda contribuir a esta alfabetización audiovisual debe enseñar a analizar los mensajes y narraciones audiovisuales, extendiendo así la capacidad meta-cognitiva que desarrolla respecto a otras materias a estos nuevos discursos y herramientas. Destacan dos tipos de medidas necesarias para abordar este objetivo (Lacasa, 2002): que los niños y adolescentes desarrollen habilidades analíticas en tanto receptores de los medios de comunicación (para detectar y entender códigos y recursos con los que aprender a interpretar e inferir significados, analizar secuencias narrativas, captar coherencias y contradicciones y desarrollar, en general, una capacidad crítica de lectura y consumo); y que aborden también un crecimiento en tanto creadores de los medios de comunicación, pensando y elaborando cómo transmitir determinados mensajes a través de distintas tecnologías y tipos de discursos narrativos y publicitarios. En los programas escolares de prevención de violencia desarrollados desde esta perspectiva (Díaz-Aguado, 2001, 2004) se incluyen actividades que permiten a los adolescentes desempeñar ambos papeles: como receptores analizan en profundidad tanto ejemplos que pudieran contener matices peligrosos con respecto a determinadas cuestiones sociales como campañas de sensibilización desarrolladas por profesionales de la publicidad audiovisual; como emisores, proceden después a la búsqueda de ideas y recursos expresivos para sus propias campañas y las realizan con medios audiovisuales. La aplicación del programa ha demostrado que el hecho de elaborar en equipos de aprendizaje cooperativo una obra compartida con otros como, por ejemplo una campaña contra el racismo, la violencia o para prevenir las drogodependencias, que pueda ser posteriormente recordada, analizada y utilizada como objeto de identificación (Bruner, 1999)- favorece considerablemente tanto la adquisición de las habilidades meta-cognitivas necesarias para la alfabetización audiovisual, como el desarrollo de aquellos valores que tales programas intentan trasmitir. Desempeñando el papel de 
expertos de lo audiovisual, se incrementa su protagonismo y se fortalece a niños y adolescentes como ciudadanos del mundo tecnológico global.

\section{La relación entre ficción y discursos publicitarios en el programa "Prevenir en Madrid"}

A modo de concreción de los principios expuestos anteriormente se incluyen a continuación tres ejemplos de cómo hemos utilizado la alfabetización audiovisual, con especial atención a los recursos y retórica publicitarios y a su relación con determinados terrenos compartidos con la ficción narrativa, en el programa "Prevenir en Madrid" (Babín, Ordóñez, Díaz-Aguado y Martínez, dirs., 2004; DíazAguado y Falcón, 2004).

Las investigaciones realizadas sobre este tema reflejan que la mayoría del profesorado estaría dispuesto a llevar a cabo acciones sistemáticas orientadas a la prevención de riesgos sociales si dispusiera de material adecuado y del apoyo necesario. Sin embargo, y a pesar de los importantes esfuerzos realizados con anterioridad en este sentido, parece seguir habiendo un desfase entre lo que la sociedad necesita de la escuela y los medios que le proporciona para conseguirlo. Así cabe interpretar, por ejemplo, que sólo el 16,6\% de los adolescentes de Madrid evaluados en la parte del estudio dedicada a la prevención de drogodependencias, por ejemplo, declarase antes de participar en este programa haber recibido información sobre este tema a través del profesorado. Con el objetivo de avanzar en la superación de estas dificultades se han elaborado los materiales del programa "Prevenir en Madrid" entre los que ocupan un lugar muy destacado sus documentos audiovisuales (tanto como herramienta para utilizar en el aula como para la formación previa del profesorado).

\subsection{El análisis de spots publicitarios como punto de partida de actividades educativas}


Para comenzar a desarrollar las habilidades de comunicación necesarias para el programa se aconseja iniciar las actividades con el análisis y debate crítico de un fragmento audiovisual fácil de comprender, de una duración breve y que genere un impacto emocional significativo: los spots de televisión -diseñados con un fin próximo al que se pretende con cada programa de intervencióndestacan así como el material más adecuado para esta fase del trabajo en el aula. Así, en el programa destinado a la prevención de la drogadicción, por ejemplo, las actividades de prevención mediante la alfabetización audiovisual parten con textos como el anuncio de la campaña de la FAD de diciembre de 1995 elaborado por la agencia BBDO, que se centra en la incomunicación entre padres hijos como una de las principales condiciones de riesgo del consumo de drogas. Se trata de una pieza de construcción metafórica clara y sencilla donde, por tratamiento de simultaneidad en montaje, un padre y un hijo aparecen en el mismo plano frente a frente, hablando a la vez sin detenerse en ningún momento, ni atender o reaccionar jamás a lo que el otro dice: la ubicación de sus cabezas en plano podría hacer parecer en un principio que efectivamente están cara a cara, pero la falta de conexión en sus miradas y el continuo flujo de cada uno de sus monólogos enuncia que no hay diálogo alguno ente ellos. El análisis de este fragmento da pie en el aula a interesantes reflexiones por parte de los adolescentes en torno al valor de la comunicación y de los requisitos que ésta necesita (la escucha, la atención, la interacción, ponerse en el lugar del otro) y activa destrezas de análisis audiovisual que no sólo se centran en la anécdota argumental o en niveles simbólicos de la imagen presentada, sino que incluso pueden llegar a tocar niveles metacomunicativos de gran complejidad. Como muestra del tipo de reflexiones que esta actividad suscita se incluye a continuación un fragmento transcrito de las que manifestaron durante el análisis del citado spot algunos alumnos de Garantía Social (de entre 16 y 18 años) de un centro de Educación Secundaria de Madrid: tras escuchar en la explicación de su profesora cómo se planifica el rodaje de una secuencia como la presentada por este anuncio (cada actor fue grabado por separado en su monólogo y ambas intervenciones se juntaron posteriormente por un sencillo mecanismo de edición), la sesión en el aula pudo derivar hacia matices muy significativos en torno a la metáfora enunciada 
por la propia escritura del spot, donde un diálogo es falso (y "no funciona") precisamente porque ha sido recreado a partir de dos monólogos superpuestos.

"Profesora: ¿Por qué creéis que los que han hecho este anuncio sobre la falta de comunicación han querido contarlo así, con este "truco", vamos a decir?... Si recordáis lo que hablábamos antes... ¿es esto comunicación, es esto un diálogo?

Alumno 1: Sí, ¿no?

Profesora: ¿Seguro?

Alumno 1: Al final hay dos hablando...

Profesora: ¿Pero hay dos hablando de verdad?

[Murmullo]

Alumno 2: Bueno, hay dos hablando pero no están hablándose de verdad... es lo que has dicho de que los grabaron a cada uno por su lado... cada uno rodó su parte y luego los juntaron en la máquina... como que nunca hablaron de verdad entre ellos, sólo repitieron cada uno lo suyo todo el tiempo, ¿no?

Profesora: Hombre, es que eso que acabas de decir es muy importante: si te das cuenta, has explicado por qué a veces la gente no se comunica aunque parezca que está junta... eso es una metáfora, ¿lo puedes volver a decir, por favor? Pero pensando ahora en la vida normal, no en un rodaje de televisión...

Alumno 2: ¿Lo que he dicho? Sí... que cada uno dice lo suyo pero sin estar en el mismo sitio... que parece que sí, que tienen un diálogo, pero en realidad no están hablando... no están hablándose.

Profesora: ¿Y eso pasa en la vida real?

Alumno 3: Pues sí... que parece que se está hablando pero no se está hablando en verdad, sin hacer caso al otro...

[Murmullo]

Alumno 1: Primero debería escuchar el padre al hijo y luego el hijo al padre, y depende de lo que le diga, pues... eso, seguir haciendo y diciendo cosas. 
Profesora: Ya, pero a veces, a lo mejor, lo que creemos los padres que os conviene a los hijos vosotros decís que no... ¿qué hacer entonces?

Alumno 1: Buscar otras soluciones, no sólo hay una solución, siempre hay más.

Alumno 2: Bueno...yo a veces, también, cuando habla mi madre paso de lo que ella dice.

Profesora: ¿Pasas, como los del anuncio?

Alumno dos: Pues sí... porque lo que me dice mi madre a veces no lo quiero oír... ya, ya sé..."

Como se observa en este fragmento de las sesiones transcritas durante el programa de investigación-acción, la reflexión suscitada a partir del spot proporcionó una oportunidad para reflexionar de forma compartida sobre los obstáculos que con frecuencia existen por ambas partes en la comunicación entre padres e hijos, ayudando a adquirir habilidades necesarias para el programa de prevención y también un esquema previo sobre el valor de la comunicación. A lo largo del programa se observa cómo van progresivamente desarrollándose estas habilidades comunicativas.

\subsection{Desarrollo de destrezas de análisis crítico de textos publicitarios}

El principal objetivo de esta segunda fase del programa es disminuir la vulnerabilidad de los niños o adolescentes frente a la influencia negativa que a veces pueden tener determinados niveles de ficción retórica utilizada por los medios de comunicación, con particular atención a ciertos discursos publicitarios, ayudándoles a desarrollar una capacidad de análisis crítico. Las actividades se centran aquí en documentos de "making-off" sobre la preparación, dirección de arte y realización de piezas publicitarias audiovisuales de diversos productos. A raíz de las explicaciones acerca de cómo se elude la mención a ciertas características o consecuencias de determinados productos, cómo se falsean texturas y superficies de los productos anunciados (mediante sustancias químicas, efectos de iluminación y retoques de posproducción), o cómo se simulan cuerpos perfectos por capas 
de photoshop o por yuxtaposición encubierta de diversas anatomías (la cara de una modelo, la mano de otra y el cuerpo de una tercera, por ejemplo), los niños y adolescentes reflexionan acerca de cómo la publicidad puede ser a veces engañosa o conducirnos a buscar ideales imposibles de conseguir. La comparación entre las creencias que los alumnos manifestaban antes de estas sesiones y la posterior toma de consciencia, revela que el análisis les ayuda a despertar unas primeras e importantes herramientas con las que detectar ciertas licencias expresivas engañosas que anteriormente interpretaban como retratos verosímiles, atractivos e imitables. A preguntas cómo “¿Qué cosas 0 cualidades imposibles de lograr nos intenta vender a veces la publicidad?", "¿Cómo puede influirnos que nos intenten vender cosas que no existen?", "¿Qué podemos hacer para evitar esta influencia negativa que a veces puede llegar desde la televisión?” o “¿Existen otras influencias distintas de la de la televisión que también pueden ser negativas?" contestan después de estos análisis con una nueva conciencia acerca de los mecanismos de creación de hábitos de consumo o de ciertos ideales de belleza física imposibles de conseguir y dañinos para la salud.

\subsection{El papel de expertos en publicidad: la evaluación y elaboración de campañas de prevención}

Esta última parte continúa el proceso desarrollado por las actividades anteriores con dos últimas sesiones de progresiva adquisición de destrezas en alfabetización audiovisual centrada en los discursos publicitarios: la evaluación de campañas de prevención y concienciación y la posterior elaboración de sus propias propuestas.

En la primera, los niños o adolescentes pasan a adoptar el papel de expertos de un jurado encargado de evaluar una serie de spots destinados al mismo objetivo específico de prevención que se está trabajando con ellos (prevención de drogodependencias, de violencia de género, de racismo o xenofobia...). Analizan una selección de anuncios procedentes de diferentes campañas, sintetizan el mensaje de cada uno y lo evalúan en relación a su claridad, valor estético y eficacia previsible. Como confirman los resultados del programa, el 
análisis que implica esta tarea evaluadora activa mecanismos muy útiles de decodificación y de detección de diferentes recursos expresivos utilizados por el lenguaje publicitario, así como una nueva capacidad reflexiva y discursiva en torno a las cuestiones concretas del programa de prevención. Como ejemplo de este tipo de resultados, citamos a continuación algunas de las reflexiones a las que llegaron alumnos de un curso de $4^{\circ}$ de Educación Secundaria Obligatoria (con edades entre 15 y 16 años) al analizar la forma expresiva y el contenido metafórico de tres spots de campañas desarrolladas por la FAD. El primero de ellos, perteneciente a la campaña de enero de 2000 hecha por la agencia SCPF, muestra un pájaro que permanece dentro de una jaula a pesar de que la puerta está abierta:

"Portavoz del grupo 1: Quiere decir que la droga es un vicio muy difícil de dejar: que es fácil de engancharse pero luego es difícil dejarlo...

Educadora social: ¿Que te encierra?

Portavoz grupo 1: Exactamente, que estás atrapado. En claridad lo hemos puntuado con un 2 sobre 5 , en valor estético un 2 y en eficacia previsible también un 2.

Educadora social: ¿Por qué habéis puesto puntuaciones tan bajas? ¿No está claro?

Portavoz grupo 1: No. Es que... un pajarito así, en una jaula... y una plumita...

Portavoz grupo 4: Hombre, dice algo más... si sale un pájaro con la puerta abierta...pues yo pienso que si se ha quedado es porque le gusta, y si no le gusta se tendrá que ir...

Educadora social: Pero a lo mejor es que las drogas tienen un poder que, aunque la puerta esté abierta ya no puedes salir...

Portavoz grupo 3: Nosotros creemos que lo que quiere decir es que, al crearte dependencia, las drogas te privan de la libertad, porque las necesitas....

Portavoz del grupo 4: Entonces cada anuncio tiene su lógica... lo del pájaro en la jaula, yo lo veo ahora... y está muy bien. ¡Cómo se puede sacar de algo tan simple algo muy grande!". 
Al intentar interpretar cada spot, los adolescentes deben adoptar la perspectiva de los creativos publicitarios expertos en la materia, situación que origina a veces algunas dificultades pero que propicia, a través del debate, una nueva toma de conciencia que no sólo atañe al mensaje que el spot pretende transmitir, sino también al mecanismo expresivo y metafórico con que se enuncia. La reacción del último alumno citado en esta transcripción, de manifiesto asombro ante su toma de conciencia de cómo se pueden expresar cualidades complejas a través de elementos más simples con intenso contenido metafórico, refleja un significativo avance en su capacidad de abstracción y de análisis crítico de los mensajes publicitarios. Por otra parte, el conflicto expresado en el grupo ante la dificultad de interpretación del spot ha permitido que la educadora pudiera explicar, de forma muy significativa y oportuna, la asociación entre el concepto de dependencia y la pérdida de libertad: esto favorece, probablemente, que el alumno portavoz del grupo 3 se apropie de dicha reflexión e interprete el mensaje que están analizando con una extraordinaria madurez, como si fuera realmente un experto que trata de sensibilizar contra los riesgos de las drogas.

Resulta también muy significativo el ejemplo de cómo analizan el spot de la campaña de la FAD de julio de 2001 elaborado por la agencia Contrapunto, donde por montaje paralelo, se muestra cómo una madre, en la cocina de su casa, comienza a sangrar por la nariz cuando su hijo consume cocaína en una discoteca:

"Portavoz grupo 2: Quiere decir que las drogas perjudican tanto al hijo como a la madre.

Educadora social: ¿Por qué?

Portavoz grupo 2: Porque cuando se acaba de drogar el hijo le sangra a la madre.

Educadora social: ¿Por qué crees que le sangra a la madre?

Portavoz grupo 2: Pues por... no sé... por la relación... es que tampoco lo sé muy bien....

Educadora social: A ver si entre todos averiguamos por qué le sangra a 
la madre la nariz... que esto es un poquito difícil....

Portavoz del grupo 4: Que haces sufrir a los más queridos por las drogas... y que yo creo que si pensases en tu familia te lo pensarías dos veces.

Educadora social: Eso ya dice mucho, pero... ¿por qué sangra?

Portavoz del grupo cuatro: Por las consecuencias, que no las sufre él, las sufren los que están a su lado....

Educadora social: Sangrar es uno de los efectos de esnifar cocaína: se rompen los vasitos de la nariz y se sangra. Es un ejemplo con el que decirnos que a la madre le está repercutiendo: uno de los efectos que va a sufrir el hijo, lo sufre ella también... ahora que sabemos esto... ¿por qué creéis que han escogido esta imagen, este ejemplo concreto de la sangre?

Portavoz del grupo cuatro: Para que impacte más... y más rápido... la sangre es roja y, yo qué sé, duele, nadie quiere ver a su madre sangrando... uff, de esto te acuerdas."

La interpretación de este spot suele plantear una especial dificultad, al exigir la integración de tres tipos de análisis: sobre el daño que el consumo de cocaína supone en los vasos sanguíneos de la nariz (del que en esta edad y contexto no suelen tener información); sobre el daño psicosocial que el consumo de drogas por parte de un joven puede producir en otra persona que le quiere, del que no suelen ser conscientes; y sobre la posibilidad de utilizar como recurso expresivo un daño físico como metáfora de consecuencias de otra naturaleza, que exige una capacidad de análisis de la que suelen carecer. Como muestra la transcripción, el conflicto suscitado ante la dificultad de interpretación de este mensaje permitió a la educadora presentar la información necesaria para la utilización de dicha habilidad, así como para la toma de conciencia del daño que el consumo de drogas de los adolescentes puede producir en otras personas.

Por último, resultan también muy significativas algunas de las conclusiones a las que estos alumnos llegaron durante el análisis del spot de la campaña de la 
FAD de julio de 2002 elaborado también por la agencia Contrapunto, donde se muestra a adolescentes en distintas situaciones (en el parque, en la discoteca...) siempre vestidos con pañales:

"Portavoz del grupo 1: Quiere decir que son niños ante las drogas. En realidad no saben lo que hacen...

Portavoz del grupo 4: Te crees que piensas como una persona mayor por meterte, y en realidad lo que te hace es comportarte como un bebé.

Portavoz del grupo 3: Ahí te tengo que aplaudir, macho [aplaude].... quiere decir que los jóvenes, una vez que han probado las drogas y les gustan, no tienen protección alguna.

Portavoz del grupo 4: Ahora te tengo que aplaudir yo [aplaude]."

La interpretación que hacen los portavoces de los grupos 3 y 4, refleja que han tomado conciencia del riesgo de que los adolescentes quieran consumir drogas para intentar demostrar que ya no son niños (aunque su efecto sea justo el contrario), así como de lo desprotegidos que quedan ante sus consecuencias inmediatas. El hecho de que cada uno exprese en público con un aplauso su aprobación a la opinión del otro, pone de manifiesto que dichas reflexiones empiezan a formar parte del pensamiento del grupo y que no es un problema expresarlas públicamente, sino que incluso pueden ser motivo de mutua admiración (cuestión especialmente significativa para estos dos alumnos, que en fases anteriores del programa habían expresado su inquietud a ser vistos como niños por sus adultos). Dentro del largo proceso generado por el programa, se observa que estas últimas actividades incluyen las habilidades desarrolladas por las fases anteriores y resultan especialmente eficaces al incorporar el rol de expertos: favorecen que se identifiquen con determinados valores expresados por adultos, incluso aunque en anteriores fases se hubiesen manifestado en contra de tales figuras educativas y de sus posibles enunciados.

Tras estas actividades de evaluación de campañas, los alumnos mantienen este rol de expertos en prevención de drogodependencias pero ya para 
elaborar sus propias campañas dirigidas a receptores de su edad, etapa final donde las nuevas destrezas comunicativas y reflexiones se asientan en la confección de un discurso propio. Entre las propuestas elaboradas por este mismo grupo de alumnos al que hacemos referencia en las últimas transcripciones, se observó una notable consciencia de aquellos recursos comunicativos aprendidos de los ejemplos publicitarios estudiados. Muchos decidieron plantear sus mensajes apelando a la empatía y el dramatismo de consecuencias físicas en personajes caracterizados como cercanos y familiares (de un modo parecido al que analizaron en el spot de la madre víctima de la adicción de su hijo), como muestra, por ejemplo, el spot diseñado por unas alumnas en torno a una canción de rap contra el consumo de "éxtasis". En la letra de la canción reúnen mucha información aprendida durante el programa acerca de las consecuencias y los daños físicos de las drogas, y deciden exponerla con una actriz que representa, cantando en primera persona, el papel de víctima portadora de un importante testimonio. Además, su nueva conciencia del papel de determinados efectos visuales les llevó a pedir que el montaje de las imágenes aplicase ciertos matices de distorsión, con los que añadir tensión al anuncio y simular la progresiva pérdida de vida de la protagonista:

"Me miro en el espejo y comienzo a preguntar:

Dios mío, ¿qué es lo que me tengo que fumar?

Me jala una amiga y comienzo a charlar:

-Tómate una pirula pa que puedas disfrutar.

Y yo le digo: -ay, ¿dónde la puedo conseguir?

-Vete para la esquina, que te la venden ahí.

Compro mi pastilla, comienzo a tragar,

cuando, de repente, comienzo a sudar.

Se me seca la boca, me da temblor...

"Ay, mi madre, ¿qué es lo me vendió?".

Me late el corazón, se me sube la tensión,

el médico me dice que es una bajá de presión.

Me da uno o dos días para poder morir: 
por culpa de una pastilla ya no estaré aquí."

En esta última fase de las actividades de alfabetización audiovisual, se tornan necesarias otras habilidades que coinciden con importantes objetivos educativos (redacción, representación plástica, dramática, musical...), poniendo de manifiesto la riqueza de lenguajes y canales de enunciación que confluyen en la confección de los mensajes publicitarios. Junto a esta superior dificultad hay que tener en cuenta que los resultados que con esta actividad pueden lograrse son de un impacto y duración también superiores: volviendo al ejemplo anterior, cabe subrayar que componer, cantar en clase el rap contra el consumo de éxtasis y hacer una primera planificación escénica para que el anuncio resulte más impactante parece haber supuesto para estos adolescentes la posibilidad de identificarse con los mensajes que dichas actividades trasmiten en mucho mayor grado que cuando comenzaron a participar en el programa $\mathrm{y}$, al mismo tiempo, evidencian una nueva consciencia de los recursos y códigos que entran en juego a la hora de conmover, seducir y captar la atención mediante mensajes publicitarios.

\section{BIBLIOGRAFÍA}

Aguinaga, J. (2005) Informe juventud en España, 2004. Madrid: Instituto de la Juventud.

Babín, F., Ordoñez, A., Díaz-Aguado, M. y Martinez, R. (Dirs.) (2004) Prevenir en Madrid. Programa de prevención de drogodependencias en contextos educativos del Ayuntamiento de Madrid. Investigación. Madrid: Ayuntamiento de Madrid

Bakan, D. (1966) The duality of human existence. Chicago: Rand McNally.

Bandura, A. (1979) Psychological mechanisms of aggression. En: Cranach et al (Eds.) Human ethology. Cambrindge, Mass.; Cambridge University Press.

Bengoechea, M.; Díaz-Aguado, M.J.; Falcon, L. (2005) Infancia, televisión y género. Guía para la elaboración de contenidos no sexistas en programas 
infantiles de televisión. Madrid: Instituto Oficial de Radio Televisión Española.

Bruner, J. (1999) La educación, puerta de la cultura. Madrid: Visor.

Buckingham,D. (2000) After the death of childhood. Growing in the age of electronic media. London: Polity Press.

Buckingham,D. (2003) La educación en medios de comunicación y el fin del consumidor crítico. Monografías virtuales OEI. Medios de comunicación y valores

democráticos.[http://www.oei.es/valores2/monografias/monografia01/reflex ion02.htm]

Catalano,R.; Hawkins,J. (1996) The social development model: A theory of antisocial behaviour. En: Hawkins,J. (Ed.) Delinquency and crime. Cambridge: Cambridge University Press.

Cembranos, F. (2004) Televisión, interacciones sociales y poder. Intervención Psicosocial, 13, 1, 27-37.

Clarembeaux, M. (2008). La educación crítica de los jóvenes en TV en el centro de Europa. Comunicar, 31; 91-98.

Clarembeaux, M. (2010). Educación en cine: memoria y patrimonio. Comunicar, $35 ; 2010,25-32$.

Clifford, B.; Gunter,B.; Mcaleer,J. (1995) Television and children. Program evaluation, comprehension, and impact. Hillsdale, New Jersey: LEA.

Cline, V.; Croft,R. ; Courier, S. (1973) Desensization of children to television violence. Journal of Personality and Social Psychology, 27,360-365.

Comisión Europea (1999) Eurobarómetro. Bruselas : European Comission,

Corroy, L. (2008). Les jeunes et les médias. París: Ministére de L'éducation Nationale, Vuibert, INA.

Díaz-Aguado, M.J.; Martínez Arias, R (2001) La construcción de la igualdad y la prevención de la violencia contra las mujeres desde la Educación Secundaria. Madrid: Instituto de la Mujer, Ministerio de Trabajo y Asuntos Sociales.

Díaz-Aguado, M.J. y Falcón, L. (2004) Prevenir en Madrid. Programa de prevención de drogodependencias en contextos educativos. 
Documentos audiovisuales para la formación del profesorado. Madrid: Ayuntamiento de Madrid.

Díaz-Aguado, M.J. (Dir.) (2004) Prevención de la violencia y lucha contra la exclusión desde la adolescencia. Tres libros y tres documentos audiovisuales. Madrid: Instituto de la Juventud. Disponibles también a través de la página web del INJUVE y desde http://mariajosediazaguado.tk

Donnerstein, E. (1998) ¿Qué tipo de violencia hay en los medios de comunicación? En: Sanmartin, J. Et al (Eds.) Violencia, televisión y cine. Barcelona: Ariel.

Eguizábal, R. (2007) Teoría de la publicidad. Madrid: Cátedra.

Huesmann, L.R.; Moise-Titus,J.; Podolski,C.; Eron,L. (2003) Longitudinal relations between children's exposure to TV violence and their aggressive and violent behavior in young adulhood: 1977-1992. Development Psychology, 39,2, pp.201-221.

Jessor, R. (1992) Risk behavior in adolescence: A psychological framework for understanding and action. Developmental Review, 12, pp. 374-390.

Geen, R.; Thomas,S. (1986) The inmediate effects of media violence on behaviour. Journal of Social Issues, 42, 7-28.

Lacasa, P. (2002) Medios de comunicación, tecnología y multiculturalidad. En: P. Pardo, P., y Méndez, L. Psicología de la educación multicultural. Madrid: UNED.

Martín Serrano, M. (1990) La participación de los medios audiovisuales en la construcción de la visión del mundo de los niños. Infancia y Sociedad, Monográfico sobre Medios de Comunicación Audiovisual, 3, 5-18.

Martín Serrano, M.; Velarde Hermida, O. (2001) Informe Juventud en España 2000. Madrid: Instituto de la Juventud.

Martinez Benlloch, I. (2002) Imagen corporal y construcción de la subjetividad. En: Mujeres jóvenes: el avance hacia la igualdad. Monografía realizada a partir del Seminario realizado en la Universidad Internacional Menéndez Pelayo. Madrid: Instituto de la Mujer.

Megias, E.(2000) Los valores de la sociedad española y su relación con las drogas. Barcelona: Fundación La Caixa. 
Paik, H.; Comstock, G. (1994) The effects of television violence on antisocial behaviour: A meta-analysis. Communication Research, 21,516-546

Plataforma por una Televisión de Calidad (2006) Manifiesto contra la telebasura. [http://www.arrakis.es/ pedra/tvbasura.htm]

Postman, N. (1994) The disappearance of childhood. New York: Vintage Books.

Potter, W. (1999) On media violence. Thousand Oaks: Sage.

Potter, W. (2001) Media Literacy. Thousand Oaks. Sage.

Rodríguez Merchán, E. (1994) Realidades y ficciones. Notas para una reflexión teórica sobre el documental y la ficción. Revista de Ciencias de la Información, número 10. Universidad Complutense de Madrid, pp. 162 a 173.

Rodríguez Merchán, E. (1996) La morbosa fascinación de la mentira, revista Academia, número 14. Abril de 1996. Páginas: Edita La Academia de Ciencias y Artes Cinematográficas de España. 